\title{
What Does the 'Postdigital' Mean for Education? Three Critical Perspectives on the Digital, with Implications for Educational Research and Practice
}

\author{
Jeremy Knox ${ }^{1}$ (D)
}

Published online: 23 May 2019

(C) The Author(s) 2019

\begin{abstract}
This paper examines what the term 'postdigital' might mean for education through the discussion of human-technology relationships. It begins with a summary of two general interpretations of the postdigital: firstly, to understand the 'post' as meaning simply 'posterior to' the digital, suggesting a different stage in the perception and use of technology; and secondly, to consider the 'post' as signalling a critical appraisal of the assumptions embedded in the general understanding of the digital. Subsequently, the paper outlines three critical perspectives on the digital with specific relevance for educational concerns. The first examines the economic rationales underpinning digital technology, focusing on the idea of the platform and the assumed benefits of sharing. The second discusses the role of the digital in educational policy and the compound effects of the metrification of institutional quality. The third section explores the digital as 'material', and the increasing attention paid to issues of labour and the exploitation of natural resources required to produce digital technologies. These perspectives suggest an understanding of the postdigital in terms of profound and far-reaching socio-technical relations, which have significant consequences for thinking about the purpose, focus, and governance of education in contemporary times.
\end{abstract}

Keywords Platform capitalism $\cdot$ Surveillance $\cdot$ Data $\cdot$ Policy $\cdot$ Labour $\cdot$ Materialism

\section{Introduction}

The principal contribution of this paper is to encourage conversation about what the 'postdigital' might mean for education. The intention is not to suggest decisive

Jeremy Knox

jeremy.knox@ed.ac.uk

1 Centre for Research in Digital Education, Moray House School of Education, The University of Edinburgh, 4.09 St John's Land, Edinburgh, UK 
definitions, but rather to continue what is emerging as a productive speculation on future relationships between technology and the project of education. As will be elaborated further, the 'digital', and hence no less the 'postdigital', have tended to be fairly marginal concerns within a general project of education that has developed around humanism (Usher and Edwards 1994; Biesta 1998; Lewis and Kahn 2010). In other words, authentic education has tended to be understood in terms of 'pure' human relationships between teachers and their students, or amongst constructivist social groupings. Where digital technology has been developed for educational purposes, it tends to be understood as a supplement or addition, applied with the intention of 'enhancing' existing pedagogical practices or learning experiences (Bayne 2015). The central aim of this paper is to highlight the need for educational practice and research to pay more attention to the ways digital technologies are shaping the core of education, rather than tending to assume that the use of technology is a distinct area of enquiry, as for example in the field of 'networked learning' (see Dirckinck-Holmfeld et al. 2012; Hodgson et al. 2014). As such, this paper will also contribute to broader understandings of the 'postdigital', as it relates to theoretical perspectives on digital technologies and cultural understandings of human-technology relationships. The definitions of this term are wide-ranging, as are the implications for many academic fields and disciplines, and this paper continues efforts to clarify what the postdigital might mean, and to underscore its importance for critical scholarship.

As the early articles in Postdigital Science and Education are demonstrating, a number of productive debates about the shifting understandings of technology in contemporary times are emerging. Defining just what is meant by the term postdigital has been a pressing concern, given the implication that humanity is encountering what to all intents and purposes we might call a 'period of change' in our relationships with digital technologies, and the social systems and institutions they appear to have become embedded within. The underlying suggestion in this paper is that, in the current moment, more attention is indeed being given to the understanding of humantechnology associations, and that the term 'postdigital' may be a useful guiding concept for this phase of theorising, particularly in education. In the spirit of avoiding fatalistic or deterministic prognostications of technological futures, however, the subsequent discussion aims to dwell in this liminal condition, and to posit the 'postdigital', not as a conclusive description of times to come, nor indeed a desired destination, but rather as a necessary juncture for reflection. This, it is hoped, will avoid the habitual narratives of 'disruption' that too often accompany accounts of supposedly radical new technologies. In this narrow view, the relationships between technology and society are framed largely in economic terms, where, ostensibly, all kinds of private enterprises and social institutions are increasingly being made amenable to the efficiencies of techno-capitalism. Part of a critical (and postdigital) response to the narrative of disruption is to point out the many continuities, histories, and endurances through which we can understand technology, rather than in terms of straightforward novelty. Importantly, then, while the postdigital is certainly an attempt to understand what is 'new' about our relationships with the digital, it is also about recognising the ways that such technology is already embedded in, and entangled with, existing social practices and economic and political systems. This would not be to suggest that such theoretical perspectives on technology are unprecedented, only that the postdigital may be a useful way of encapsulating and developing critical discussions of the use of contemporary digital technologies. 
The tendency in postdigital theorising has been to suggest two different general positions. The first, and the more straightforward interpretation, is to understand the 'post' as meaning simply 'posterior to', suggesting a different stage in the perception and use of technology. The postdigital in this sense is often, as Fuller suggests, understood as 'after the digital has lost its novelty or salience' (Fuller and Jandrić 2019: 215), and is concerned with understanding the digital as a moment in history, albeit a recent one. As Cramer (2015: 13) suggests, it is the historicisation of our 'fascination with ... systems and gadgets'. Indeed, this view appears to have entered contemporary vernacular, generally expressing a kind of resistance to what appears to be an increasing obsession with digital systems in everyday social life (see Jenkins 2014). While Fuller is sceptical about the intellectual merits of such a view (Fuller and Jandrić 2019), and Cramer (2015) questions its implied romanticism, there is perhaps some value here in attempting to understand changes in societal relationships with technology. For example, understanding how disillusionment with particular technologies manifests, and placing this in the context of historical responses to industrialisation, for example, would seem to be a more productive intellectual pursuit that relying on the often-quoted 'hype cycle' from Gartner (2019), particularly prominent as a kind of essentialist justification for educational technology trends. Even where the postdigital is understood simply as a periodisation, then, it may offer richer social and cultural insights than a straightforward measure of consumer habits.

The second general position on the postdigital can be understood to draw on what one might call a significant tradition of 'post' theorising. This broad approach has focused critical attention on modernism (e.g. Lyotard 1986), humanism (e.g. Badmington 2000), and colonialism (e.g. Said 2003), to name just a few of the prominent examples, and suggests a much more nuanced and critical view of humantechnology relations that might be developed under the term postdigital. While the specific and divergent concerns of these areas of scholarship are too vast to articulate fully here, it is suggested that some generalisation, however flawed, is helpful. What might be most apparent in this 'post' theorising is a challenge to modernist grand narratives. For the purposes of this paper, one might therefore recast this approach as a questioning of the dominant chronological understanding of technology development (in which notions of saturation and a loss of novelty as discussed previously seem to be logical conclusions). In other words, the postdigital might be usefully developed as an alternative view of human-technology relationships, and one that challenges commonsense ideas about the sequential progress of technology, which tend to limit responses to either an embracing of futuristic technological enhancement, or the desire for a sentimental return to a more 'natural' existence. What if the postdigital serves as a useful term to indicate a 'mixing up' of the neat chronology that positions the digital as either the zenith of technical progress, propelling humanity towards social equality, or as a dehumanising force, set to rob individuals and communities of authentic life experience? In this sense, work in the postdigital can be understood to follow from long established work in the philosophy of technology (e.g. Feenberg 1999), which has long-challenged assumptions about what technology is, and how it relates to the human condition. The postdigital may be a useful term, both to encapsulate this general perspective, and to indicate a specific critical engagement with the contemporary 'digital', as distinct from notions of technology in general. This discussion of particular character of the digital will be elaborated in subsequent sections. 
With such a view of the postdigital, notions of novelty and salience, which appear to lack some sensitivity to differing global contexts in which access digital technologies may vary considerably, might be better understood as pervasiveness. In this sense, the postdigital might be understood as no longer viewing the digital as 'other' to everyday life. The notion of the pervasiveness of the digital would not necessarily collapse tangible differences in developed and less developed contexts, but rather signals the ways that digital systems both directly and indirectly shape global society. For example, individuals and particular societies might be directly influenced by the use of mobile phones - through which one might, for example, perceive a range of social or psychological consequences - but they might also be indirectly influenced by the industry that produces such devices, perhaps through environmental or economic impact. What this acknowledgement of indirect relations does is shift the understanding of technology, away from tangible (and quite literally 'to hand') devices and gadgets, towards a view of entangled relationships, in which the digital is already embedded in what we might usually distinguish as the social, economic, and political. This represents an important frontier of understanding, particularly for education, for which the postdigital offers some useful insights.

Following from Badmington's (2000: 2) helpful definition of the 'post-' prefix as 'a convenient shorthand', in his case for 'a general crisis' in 'humanism', the limitations of the term postdigital must be acknowledged. The postdigital, it is suggested, might be better understood as a period of transition in understanding, rather than a robust concept. Just as for Badmington's 'posthumanism', therefore, the postdigital may signal both the need to contend with a turning point in our comprehension of the digital, as well as our general inability to encapsulate just what this new condition might be. Cramer's (2015: 13) work on aesthetics puts this somewhat more frankly: the postdigital is 'a term that sucks but is useful'. Rather than promote the need to rush to a coherent definition, therefore, this paper suggests some value in lingering in the meaning-making processes at play. Furthermore, while Fuller may indeed be correct that the more intellectually ambitious definition of the postdigital would be 'after the digital becomes the master narrative of our world' (Fuller and Jandrić 2019: 215), one might not want to invest so much in the term itself. It seems unlikely that 'postdigital' would survive as a catch-all label for such intellectual pursuits. Indeed, moving away from this term would not be a loss, but rather a measure of the success of dwelling in its definition.

\section{(Post)Digital Education}

While theories of the postdigital have tended to surface in the humanities, for example in music composition (see Cascone 2000) and contemporary art (see Berry and Dieter 2015), they have had relatively little impact in education research. One of the more obvious reasons for this may be the general lack of rigorous engagement with the very idea of technology in educational research (see Oliver 2011, 2016), which one might assume is required in order to begin to consider the relevance of a term such as the postdigital. In other words, mainstream education would have to see itself firstly as 'digital', as fundamentally involved with technology, in order to subsequently view the postdigital as a meaningful condition, to which it needed to pay attention. That 
mainstream educational research has not engaged more substantively with digital technology is indicative, not only of education's foundational relationship with humanism (Usher and Edwards 1994; Pedersen 2010; Biesta 1998; Kakkori and Huttunen 2010; Lewis and Kahn 2010; Knox 2016), but also, relatedly, of its persistent separation of an authentic inner 'humanness' from external and alien 'technology'. The project of education is overwhelmingly viewed as a matter of human development, whether in the form of individual behaviours, cognitive processes, or social constructions, in which technology only features in a supporting role, typically as an uncritical 'enhancement' for learning (see Bayne 2015). However, returning to the critical dimensions of the aforementioned 'post-' theorising, it is important to highlight, not only the fundamental challenge to modern distinctions between the social and the natural (for example Latour 1993), but also the question of whether the accepted (modernist) view of digital technology was ever a coherent one. In other words, if education has never been digital — where the digital is taken to mean instrumentalism and essentialism (see Hamilton and Friesen 2013) - then the postdigital might be considered a rather productive (re)turn to core educational concerns, albeit in a context of a wider society already entangled with, and constituted by, pervasive digital technologies.

The subsequent sections of this paper suggest three different perspectives on shifting relationships with digital technology, with specific relevance for educational concerns. The first will examine the economic rationales underpinning educational technology, focusing on the idea of the platform and the assumed benefits of sharing. The second will discuss the role of the digital in educational policy, and the compound effects of the metrification of institutional quality. The third section will explore the increasing attention paid to issues of labour and the exploitation of natural resources required to produce digital technologies.

\section{Digital as Capital}

Recent public scandals involving technology have played a significant role in challenging the tendency to understand the digital as straightforwardly a social form of media, and inciting a proliferation of academic research on the surveillance cultures and the profit-seeking motives of the technology industry. Key events include the Edward Snowden affair (see Macaskill and Dance 2013), which highlighted the extent of the technology industry's collaboration with the US government to collect data on citizens, and which 'launched a vociferous debate about big data, surveillance and the public good' (Boellstorff 2015: 90), and the more recent Facebook and Cambridge Analytica scandal (see Cadwalladr and Graham-Harrison 2018), which revealed significant political meddling with social media data. As such, public awareness seems to be shifting towards the idea that the technology industry might not be entirely governed by a benevolent interest in connecting people and improving social life, as one might perceive from its promotional machinery, but is also underpinned by a rampant desire for market share and profit derived from the mining of user data. A growing body of work is examining the ways in which 'twenty-first century advanced capitalism' is 'centred upon extracting and using a particular kind of raw material: data' (Srnicek 2017: 39). In particular, Srnicek (2017: 88) focuses on the 'platform' as the key site of 
critical enquiry, which has become 'an increasingly dominant way of organising businesses so as to monopolise ... data, then extract, analyse, use, and sell them'.

It is precisely such perspectives that educational research could pay more attention to, in the context of increasing technology industry entrepreneurialism being directed towards education, premised on the idea of generating value from student data. Massive Open Online Courses (MOOCs) exemplify the attempts to 'disrupt' the education sector with a platform business model (Knox 2016). However, as Srnicek's work highlights, 'platform capitalism' needs to be understood in broad economic terms, with tendencies towards 'expansion of extraction, positioning as a gatekeeper, convergence of markets, and enclosure of ecosystems' (Srnicek 2017: 98). MOOCs and other educational platforms are therefore better understood, not just as educational 'tools' or specific items of software, but as part of wider economic shifts that are restructuring education according to the promise of data, and the habitual claims of precision and efficiency which accompany them. Importantly, this means that education itself is increasingly being seen as the business, not just of established (public) educational institutions, but of (private) technology companies who have access to data. It should perhaps come as no surprise, then, that the development of 'personalised' learning systems, that supposedly customise educational experiences with the use of data, are being developed by none other than social media giant Facebook (see Herold 2016). What appears most significant in the platform model is therefore the increasing convergence of education with the wider 'datafied' society, for which educational research would benefit from more outward-facing and interdisciplinary approaches. Certainly for education researchers specifically interested in technology, there has been a notable tendency to be 'more interested in sustaining inward-focused discussions rather than entering into productive dialogue with work in other areas' (Oliver 2016: 53).

Prominent areas of educational research and practice have long been influenced by notions of the web as inherently 'open' and 'social' (e.g. Brown and Adler 2008), through which digital technology can be too easily aligned with the idea of learning as 'social constructivism', and a general sense of education as a public institution. Further, the notion of the network, an idea influenced by the connective capacities of the web, has served as an important framework for understanding learning activity in the era of digital technologies. While this is represented by research in 'networked learning', most prominently through a biennial conference and associated book series (see DirckinckHolmfeld et al. 2012; Hodgson et al. 2014), it has also motivated more radical claims, such as the proposed theory of 'connectivism' (McAuley et al. 2010). However, while these ideas have generated significant and productive educational research communities, the rise of the platform model is necessitating more in the way of critical considerations of the digital tools and social media utilised for educational purposes. As Srnicek (2017: 112) suggests, the platform is 'driving the move from an open web to increasingly closed apps', through which private companies can better collect, manage, and benefit from data.

It seems increasingly important to recognise that in this shift from the 'open web' to the 'platform', the opportunities for undertaking education with digital technologies can be viewed as part of a 'sharing economy' that involves the 'commercialization of communitarianism' (Birchall 2017: 7). While there has been much encouragement to utilise social media for educational activity, and as such bypass supposedly outdated 
institutions, this activity undoubtedly opens and exposes education to the economics of the data-driven technology industry. Birchall suggests that the idea of sharing, which has been foundational to both the technical and cultural formations of the web, is as follows:

one concerned no longer with open and nonaccumulative peer-to-peer communication but rather with a "sharing" of the journey, searches, and data transfers, from one IP address or an individual user with the Web publisher and, often, third parties. (Birchall 2017: 15)

This does not mean that conducting educational activity online cannot be genuinely meaningful and emancipatory, but rather that, at the very same time, it should be recognised as fuelling a capitalistic desire for data. Education research needs to develop the concept of learning within this frame, rather than rely on the rather tired notion of the autonomous, self-directing learner, straightforwardly utilising networks for personal enhancement (e.g. Richardson and Mancabelli 2011). Rather than fall back on the other extreme of assuming that the digital can be rejected or avoided entirely, one might look to Birchall's (2017: 18) notion of 'shareveillance': 'the condition of consuming shared data and producing data to be shared in ways that shape a subject who is at once surveillant and surveilled'. The trajectory of education appears to be heading towards a pervasive regime of data collection through which one's recognition as a learner (and teacher) is increasingly constructed. In other words, to count as a learner (or teacher), one must be counted. As Boellstorff (2015: 103 emphasis original) suggests, 'the rise of big data is accompanied by a discourse that links surveillance to recognition, that frames surveillance as a form of belonging', and it is difficult thus to perceive being involved in education without being 'datafied' in some form. Therefore, more work is needed to understand educational identity and subjectivity in an increasingly digitised education, not simply as innate human characteristics brought out through technologyenhanced teaching and learning, but as factors inextricable from the broader workings of the data-driven economy. The key question here is how notions of educational identity and belonging can be retrieved as public, collective ideals. In this sense, troubling the view of the digital as straightforwardly and exclusively open, social, and emancipatory - an assumptive tendency perhaps most prevalent in aspects of the open education movement (e.g. McAuley et al. 2010) — is not to suggest an end to the idea of an optimistic and affirmative education. Indeed, there is good reason to think that utopic visions of technology for education could be reclaimed where public, collective ideals are built-in to the digital systems used for educational activity, instead of allowing private enterprise to increasingly encroach on teaching and learning practices through corporate platform models. Developing an understanding of how such an approach might work in practice might constitute a productive direction for educational research in the postdigital.

\section{Digital as Policy}

The prevailing view of digital education — or indeed e-learning, and computer-assisted learning as it might once have been termed-has been as a distinct research topic or 
teaching practice largely on the periphery of a core project of education, concerned overtly with a kind of pure human development devoid of technology. Digital education has tended towards claiming a progressive, unconventional, and anti-institutional stance, thus positioning itself as something other than the authentic, mainstream, and humanist project of education.

A key aspect of the postdigital perspective in education is the troubling of this distinction, as the digital becomes much more embedded in the underlying and unseen systems of mainstream education activity. Chiefly, this can be located in the transformation of education governance where 'data-based software platforms, infrastructures and projects are increasingly being stitched on to the kinds of policy work that governs educations systems, institutions and practices' (Williamson 2017: 66). As Williamson (2017) notes, underpinning such moves is a government-driven desire for performance, measurement, inspection, evidence, and judgement in education, for which data seem to provide tangible promise. As such, one must recognise the 'data imaginary' at work across contemporary society, including education, in which the digital is imbued with all kinds of advantageous properties. In this imaginary, data are 'said to fix bugs, remove abnormalities, drive change, render competitive, free up time, reveal what is hidden, and so on' (Beer 2019: 132). In education, this imaginary is increasingly translated into rationales for making educational activity more visible and efficient. As Williamson (2017) stresses, the promise of data also ushers in new forms of educational governance that are characterised by decentralisation, new kinds of technical expertise. Further:

Data processing software, the organisations that produce and enact it, and the imaginaries that animate its production and use, are all now part of the networks that allow education to be governed at a distance and at speed (Williamson 2017: 68)

As Williamson (2017: 82) elaborates, this manifests in routine and mundane data collection in schools, which are 'often turned into simplified presentations', such as that provided by the Department for Education in the UK, allowing various audiences to search school performance data. Commercial products are also emerging, such as 'School Finder', which 'aggregates and combines data from school performance tables, the School Census, Ofsted data, Ordnance Survey data, and information from schools' own promotional and marketing materials' (Williamson 2017: 83).

However, these 'intimate datascapes' (Williamson 2017: 86) can be understood, not only just as providing new ways of measuring and viewing educational institutions through data, but also as instruments which have significant influence on educational practice. O'Neil provides a salient example of this in an examination of the algorithmically infused US News college ranking system (O’Neil 2017). Here, the attempt to measure 'educational excellence' is shown to derive from 'proxies that seemed to correlate with success' (O’Neil 2017: 52). However, the approach ended in 'an almost endless spiral of destructive feedback loops' (O’Neil 2017: 54). This included administrators' attempts to drive up rankings by focusing specifically on the narrow measures constitutive of the ranking score, and produced not only a kind of arms race which influenced the rise in tuition fees, but also a 'vast ecosystem' of consultancy firms, recruitment organisations, coaches, and tutors, developed to respond to the algorithmic 
model of excellence (O’Neil 2017). Ultimately, what this metrification of education produces - a quantification of educational excellence, and its intensification and scale through powerful algorithmic processes - is the amplification of inequality in education. For O'Neil (2017: 65), the process 'tilts against needy students, locking out the great majority of them - and pushing them down a path toward poverty. It deepens the social divide'.

We might return here to Fuller's definition of the postdigital as 'after the digital becomes the master narrative of our world' (Fuller and Jandrić 2019: 215), and suggest the forming of an increasingly powerful discursive regime in education based on data, but also a concern for its unintended consequences. In what has been outlined above, one might view the digital as to all intents and purposes, indivisible from educational policy. Importantly for the discussion of the postdigital, the kind of 'educational technology' being discussed here is not in the form of any classroom gadget, but is rather something much broader, that encompasses the imagined benefits of data, vast data collection infrastructures, complex data-driven technologies and their associated expertise, and the scaled effects of algorithmic and networked systems. Further, while perhaps invisible in everyday educational practice, this view of the digital is certainly not passive, and has significant influence on the strategic activity and financial capacity of institutions. In this sense, the digital appears to be operating on the core, mainstream of education, rather than merely manifesting in studies of specific technologies employed for particular teaching and learning situations. Such a postdigital perspective, as this is suggested to be, might signal the end of 'digital education' as a distinct subfield of educational research and practice, and encourage a view of education as already entangled with data and subject to the imaginaries and technical processes of the datafied society.

\section{Digital as Material}

The third and final interpretation of the postdigital relates to a growing interest in surfacing the often-hidden material dimensions of the digital, such as the human labour required to produce and sustain technology, and the infrastructures and substances required to produce it. This might be seen as contrasting a predominant understanding of the digital as 'virtual', where technology tends to be viewed as something beneficially intangible, and able to bypass many of the limitations of physical, embodied reality. Such views have origins in early portrayals of the web, which cast materiality as something of an inconvenience, to be overcome by technological advancement. For example, with reference to the work of Karl Popper, Benedikt (2000: 21) suggests, 'cyberspace, we now see, is nothing more, or less, than the latest stage in ... evolution ... with the ballast of materiality cast away - cast away again, and perhaps finally'. Qiu provides a particularly important critical view here:

These clichés have been repeated too often and for too long - we live in a "postindustrial society"; our economy is becoming "weightless" and "friction-free"; our world is being "flattened" by computers, airplanes, and freighters. This may be true for those who choose to focus exclusively on content, on the virtual and 
ether, while ignoring the vast and growing body of electronic equipment we have to use to access and sustain whatever cyberspace contains (Qiu 2016: 11-12)

This focus on the industrial production of digital technology delves beneath the surface of slick devices and their marketing campaigns to highlight the very real labour conditions through which they are assembled. In other words, the digital requires bodies, and specifically labouring bodies, in order to bring about the kind of advantages often assumed in the contemporary datafied society. In other words, efficiency in one context is dependent on manual labour in another. As Qiu (2016: 13) reminds us, '[t]o make these tangible products, there has to be a global system to assemble, polish, pack, and transport them before they can be used to receive, generate, and circulate content, and to facilitate social networking'. For Qiu (2016: 6), whose work focuses on highly questionable manufacturing conditions in China - the 'workshop of the world' for electronics - this is part of what constitutes a form of modern slavery.

Educational research and practice could pay more attention to this aspect of the political economy of education technology development, or at least to the production of digital devices that end up being put to use in educational contexts. This seems particularly important for educational initiatives that view the application of digital technology as an explicit matter of social justice, such as the open education movement (Funes and Mackness 2018). While Funes and Mackness (2018) examine important exclusions in the structure of social media interactions that question the underlying assumptions of 'openness' in open education, this kind of critique could also useful extend to the material; identifying the tensions and contradictions in using digital devices to promote social justice through education, while the production of those very same devices is demonstrably replete with the inequalities and injustices of labour exploitation.

A significant part of this largely unseen system of labour also involves working with data. As Andrejevic et al. suggest:

If one of the casualties of a fascination with the 'virtual' character of software, applications, code and data has been a shift away from political-economic approaches to the media, the reliance of data mining on capital-intensive infrastructure reminds us of the ongoing salience of political-economic concerns (Andrejevic et al. 2015: 385)

This is not to deny that some kind of educational emancipation might take place through the use of a particular digital technology 'over here', only that it might also be acknowledged that such an outcome is likely to be premised on some other kind of oppression 'over there'. Part of the postdigital sensibility, therefore, may be to recognise that there is a social cost to the availability of digital technologies, and that they do not exclusively derive from clever 'disruptions' or 'innovations' in Silicon Valley. Indeed, educational research might also pay particular attention to the growing use of human labour in the production of so-called 'intelligent' systems. While artificial intelligence (AI) underpinned by machine learning is garnering much attention in the high-profile visioning of educational futures (e.g. Luckin et al. 2016), surfacing the often-concealed production process of such technologies seems as important as ever. While workers in China assemble digital devices, they are also increasingly employed 
to organise data for AI systems to process (see Li 2018). So-called 'data labelers', who constitute an often unseen and 'blue-collar' form of technical talent — as opposed to the 'data scientist' as the 'sexiest job of the 21 st century' (Davenport and Patil 2012)—work long hours on repetitive tasks designed to improve the efficiency and accuracy of AI systems. These workers,

sit in front of computers for eight hours a day and click on dozens of photos, outlining backgrounds, foregrounds, and specific objects, all according to the specifications of a client who is working on artificial intelligence. (Wu 2018)

The industry is not limited to China, with recent reports of blossoming enterprises in Kenya (Lee 2018). While Kenyan workers undertake similar routine tasks for low wages, Lee (2018) suggests that 'the information prepared here forms a crucial part of some of Silicon Valley's biggest and most famous efforts in AI'. Alongside the issues of labour exploitation here, one might also perceive a different kind of 'AI and education'; one invested in a quality training of machine learning technology rather than the educational prospects of those involved in the data labelling work.

In additional to labour concerns, increasing attention is being given to the related environmental cost of the digital. Emejulu and McGregor (2019: 134) point out the 'everyday violence' embodied in digital devices, which, through their reliance on the rare-earth metal Tantalum, as well as tin, represent 'a scramble to control and exploit ... natural resources' within 'a very old and familiar materialist struggle played out for the benefit of supposedly new digital citizens'. Alongside the human atrocities linked to this exploitation of natural resources, they also attest to the 'pollution of drinking water, loss of soil fertility, decreasing fish stocks and loss of 60-70\% of local coral' from tin dredging (Emejulu and McGregor 2019: 135). As such, they call for a specifically educational outcome: a 'radical digital citizenship in which critical social relations with technology are made visible and that emancipatory technological practices for social justice are developed' (Emejulu and McGregor 2019: 144). What this seems to imply is that education might move beyond a common instrumentalism that views educational technologies as largely invisible 'tools' for pedagogical ends, and incorporate ways of making digital devices, and their production, more perceptible, as opportunities for critical discussion and practice. This would appear to be a productive trajectory for the re-evaluation of the digital in education that might be encapsulated by a turn to the postdigital.

\section{Conclusions}

This paper has suggested that the postdigital might be understood as a kind of 'holding to account' of many of the assumptions associated with digital technologies in education. However, this is not to suggest that critical perspectives on digital technology are somehow new, but rather that, in the contemporary moment of data-intensive processing, we may need to rearticulate and redirect these critiques towards the centre ground of education. Neither is this a suggestion that the postdigital serves as an umbrella term for all critical work; only that educational researchers might view the postdigital as a particular turn towards acknowledging the political economy of the digital. 
Through various definitions of the postdigital, this paper has suggested theoretical perspectives that can be mobilised for critical educational research in an era of increasing digitisation. This has involved a call to expand the scope of educational research, beyond a tendency to understand technology in terms of tangible devices and gadgets, towards a broader understanding of the socio-technical systems within which the project of education is constituted. Three examples were elaborated: firstly, a discussion of the increasing entanglement of digital technology in capitalism and capitalist society, in which data has become a valuable resource, and education itself has become a site for its associated entrepreneurialism. As such, educational practices which have advocated communication and exchange through social networks as an emancipatory form of learning may need to develop an acknowledgment of the sharing economy that embroils educational activity in co-constitutive relations with the digital; secondly, an examination of the increasing use of digital technologies in the governance of education in which the concerns of 'digital education' are quickly becoming the concerns of education in the general. This section discussed the increasing metrification of institutional qualities, and the compound negative effects of algorithmic ranking. As such the critical sensibilities suggested of the postdigital might be better understood, not as directed towards technology as an isolated category, but towards much more fundamental purposes of educational activity itself; thirdly, an exploration of the material dimensions of the digital, focusing on labour practices and natural resources. Here, the liberatory potentials of the digital were contrasted with the oftenoppressive working conditions of those assembling hardware devices, as well as training AI software through routine and repetitive tasks. The environmental cost of the digital was also highlighted in a call for educational practices to acknowledge the social and material relations through which technologies are produced. Specifically, this drew upon the idea of a 'radical digital citizenship', through which:

individuals and groups committed to social justice critically analyse the social, political and economic consequences of digital technologies in everyday life and collectively deliberate and take action to build alternative and emancipatory technologies and technological practices (Emejulu and McGregor 2019: 140)

This appears to be one valuable way of perceiving, not only the critical thrust of the postdigital as a theoretical intervention in education, but also the suggestions of a possible form of practice through which educational activity might productively engage in the building of its own technologies. While Emejulu and McGregor (2019) are sceptical about their suggestions for a radical digital citizenship, such a form for postdigital education also seems somewhat unlikely given the immense power of the technology industry and its growing influence on educational activity. Nevertheless, as part of what might be considered an ongoing struggle to define education in an increasingly datafied society, such an approach might point the way to reclaiming an affirmative form of the digital - a 'postdigital' - for continuing educational research and practice. 
Open Access This article is distributed under the terms of the Creative Commons Attribution 4.0 International License (http://creativecommons.org/licenses/by/4.0/), which permits unrestricted use, distribution, and reproduction in any medium, provided you give appropriate credit to the original author(s) and the source, provide a link to the Creative Commons license, and indicate if changes were made.

\section{References}

Andrejevic, M., Hearn, A., \& Kennedy, H. (2015). Cultural studies of data mining: introduction. European Journal of Cultural Studies, 18(4-5), 379-394. https://doi.org/10.1177/1367549415577395.

Knox, J. (2016). Posthumanism and the massive open online course: contaminating the subject of global education. New York and London: Routledge.

Badmington, N. (2000). Introduction: approaching posthumanism. In N. Badmington (Ed.), Posthumanism (pp. 1-10). Basingstoke: Palgrave.

Bayne, S. (2015). What's the matter with 'technology-enhanced learning'? Learning, Media and Technology, 40(1), 5-20. https://doi.org/10.1080/17439884.2014.915851.

Beer, D. (2019). The data gaze: capitalism, power, and perception. London: Sage.

Benedikt, M. (2000). Cyberspace: first steps. In D. Bell \& B. M. Kennedy (Eds.), The Cybercultures Reader (2nd ed.). Abingdon: Routledge.

Berry, D. M., \& Dieter, M. (2015). Thinking postdigital aesthetics: art, computation, and design. In D. M. Berry \& M. Dieter (Eds.), Postdigital aesthetics: Art, computation, and design. New York: Palgrave Macmillan.

Biesta, G. (1998). Pedagogy without humanism: Foucault and the subject of education. Interchange, 29(1), 116.

Birchall, C. (2017). Shareveillance: the dangers of openly sharing and covertly collecting data. Minneapolis: University of Minnesota Press.

Boellstorff, T. (2015). Making big data, in theory. In T. Boellstorff \& B. Maurer (Eds.), Data, Now Bigger and Better! (pp. 87-108). Chicago: Prickly Paradigm Press.

Brown, J. S., \& Adler, R. P. (2008). Minds on fire: open education, the long tail, and learning 2.0. Educause Review, 43(1), 16-32. http://www.educause.edu/ero/article/minds-fire-open-education-long-tail-andlearning-20. Accessed 20 May 2019.

Cadwalladr, C., \& Graham-Harrison, E. (2018). Revealed: 50 million Facebook profiles harvested for Cambridge Analytica in major data breach. The Guardian. https://www.theguardian.com/news/2018 /mar/17/cambridge-analytica-facebook-influence-us-election . Accessed 20 May 2019.

Cascone, K. (2000). The aesthetics of failure: "post-digital" tendencies in contemporary computer music. Computer Music Journal, 24(4), 12-18.

Cramer, F. (2015). What is). Postdigital'? In D. M. Berry \& M. Dieter (Eds.), Postdigital aesthetics: art, computation, and design. New York: Palgrave Macmillan.

Davenport, T. H., \& Patil, D. J. (2012). Data scientist: the sexiest job of the 21st century. Harvard Business Review. https://hbr.org/2012/10/data-scientist-the-sexiest-job-of-the-21st-century. Accessed 20 May 2019.

Dirckinck-Holmfeld, L., Hodgson, V., \& Mcconnell, D. (2012). Exploring the theory, pedagogy and practice of networked learning. Dortrecht: Springer.

Emejulu, A., \& McGregor, C. (2019). Towards a radical digital citizenship in digital education. Critical Studies In Education., 60(1), 131-147. https://doi.org/10.1080/17508487.2016.1234494.

Feenberg, A. (1999). Questioning technology. London: Routledge.

Fuller, S., \& Jandrić, P. (2019). The postdigital human: making the history of the future. Postdigital Science and Education., 1(1), 190-217. https://doi.org/10.1007/s42438-018-0003-x.

Funes, M., \& Mackness, J. (2018). When inclusion excludes: a counter narrative of open online education. Learning, Media and Technology, 43(2), 119-138. https://doi.org/10.1080/17439884.2018.1444638.

Gartner (2019). Gartner Hype Cycle. https://www.gartner.com/en/research/methodologies/gartner-hype-cycle. Accessed 20 May 2019.

Hamilton, E.C., \& Friesen, N. (2013). Online education: a Science and technology studies perspective. Canadian Journal of Learning and Technology, 39(2). https://doi.org/10.21432/T2001C.

Herold, B. (2016). Facebook's Zuckerberg to bet big on personalized learning. Education Week. https://www. edweek.org/ew/articles/2016/03/07/facebooks-zuckerberg-to-bet-big-on-personalized.html . Accessed 20 May 2019. 
Hodgson, V., de Laat, M., McConnell, D., \& Ryberg, T. (Eds). (2014). The design, experience and practice of networked learning. Dortrecht: Springer.

Jenkins, S. (2014). In this post-digital age, we still thrill to the power of live. The Guardian, 20 June. https:/www.theguardian.com/commentisfree/2014/jun/20/post-digital-thrill-power-of-live-antidoteglastonbury. Accessed 20 May 2019.

Kakkori, L., \& Huttunen, R. (2010). The Sartre-Heidegger controversy on humanism and the concept of man in education. Educational Philosophy and Theory, 44(4), 351-365. https://doi.org/10.1111/j.14695812.2010.00680.x.

Latour, B. (1993). We Have Never Been Modern. Cambridge: Harvard university Press.

Lee, D. (2018). Why big tech pays poor Kenyans to teach self-driving cars. BBC Technology, 3 November. https:/www.bbc.com/news/technology-46055595. Accessed 20 May 2019.

Lewis, T. E., \& Kahn, R. (2010). Education out of bounds: reimagining cultural studies for a posthuman age. New York: Palgrave Macmillan.

Li, Y. (2018). How cheap labor drives China's A.I. ambitions. New York Times, 25 November. https://www. nytimes.com/2018/11/25/business/china-artificial-intelligence-labeling.html. Accessed 20 May 2019.

Luckin, R., Holmes, W., Griffiths, M., Forcier, L.B. (2016). Intelligence unleashed an argument for AI in education. Pearson Report. https://static.googleusercontent.com/media/edu.google. com/en//pdfs/Intelligence-Unleashed-Publication.pdf . Accessed 20 May 2019.

Lyotard, J.-F. (1986). The postmodern condition: a report on knowledge. Manchester: Manchester University Press.

Macaskill, E., \& Dance, G. (2013). NSA files decoded: what the revelations mean for you. The Guardian, 1 November. https:/www.theguardian.com/world/interactive/2013/nov/01/snowden-nsa-files-surveillancerevelations-decoded\#section/1. Accessed 20 May 2019.

McAuley, A., Stewart, B., Siemens, G., \& Cormier, D. (2010). The MOOC model for digital practice. https://oerknowledgecloud.org/sites/oerknowledgecloud.org/files/MOOC_Final.pdf . Accessed 20 May 2019.

O'Neil, C. (2017). Weapons of math destruction: how big data increases inequality and threatens democracy. London: Penguin.

Oliver, M. (2011). Technological determinism in educational technology research: some alternative ways of thinking about the relationship between learning and technology. Journal of Computer Assisted Learning, 27(5), 373-384. https://doi.org/10.1111/j.1365-2729.2011.00406.x.

Oliver, M. (2016). What is technology? In N. Rushby \& D.W. Surry (Eds.), The Wiley handbook of learning technology (pp.35-57). Hoboken: Wiley-Blackwell. https://doi.org/10.1002/9781118736494.ch3.

Pedersen, H. (2010). Is 'the posthuman' educable? On the convergence of educational philosophy, animal studies, and posthumanist theory. Discourse: Studies in the Cultural Politics of Education, 31(2), 237250. https://doi.org/10.1080/01596301003679750.

Qiu, J. L. (2016). Goodbye iSlave: a manifesto for digital abolition. Urbana: University of Illinois Press.

Richardson, W., \& Mancabelli, R. (2011). Personal learning networks: using the power of networks to transform education. Bloomington: Solution Tree Press.

Said, E. (2003). Orientalism. London: Penguin.

Srnicek, N. (2017). Platform capitalism. Cambridge: Polity Press.

Usher, R., \& Edwards, R. (1994). Postmodernism and education: different voices, different worlds. London: Routledge.

Williamson, B. (2017). Big data in education: the digital future of learning, policy and practice. London: Sage.

$\mathrm{Wu}, \mathrm{H}$. (2018). China is achieving AI dominance by relying on young blue-collar workers. Motherboard, 21 December. https://motherboard.vice.com/en_us/article/7xyabb/china-ai-dominance-relies-on-young-datalabelers . Accessed 20 May 2019. 